\title{
Screening panoramic radiology of adults in general dental practice: radiological findings
}

\author{
V. E. Rushton, ' K. Horner, ${ }^{2}$ and H. V. Worthington, ${ }^{3}$
}

\begin{abstract}
Aim To identify the radiological findings from routine screening panoramic radiographs taken of adult ( $\geq 18$ years) patients in general dental practice.

Method Forty-one general dental practitioners (GDPs) who routinely took panoramic radiographs of all new adult patients were recruited. In total, they submitted 1,818 panoramic radiographs of consecutive patients along with basic patient information, radiological reports and treatment plans. The radiographs were also reported by 'experts' (consensus of two dental radiologists). Radiological findings were recorded from the GDP assessments (dentist RY), the experts (expert RY), after exclusion of findings that would have been seen on posterior bitewing radiographs (MRY) and after exclusion of findings of no relevance to treatment (MRYT).

Results There was no significant difference in age profile between the study sample and Dental Practice Board population figures $(P=0.26)$. No radiographs other than the panoramic radiograph had been taken for $57.1 \%$ of patients. For the GDP assessments, only $4.6 \%$ of patients had radiographs with no radiological findings, while for the experts this proportion was $3.1 \%$. With the exception of the assessment of periodontal bone loss, the experts diagnosed significantly greater proportions of cases as having positive radiological findings. Agreement between dentist and expert assessments varied greatly. When findings from bitewing radiographs were excluded, no radiological findings were recorded on the radiographs of $17.2 \%$ of patients. When proposed treatment plans were taken into account, the majority of patients' radiographs $(56.3 \%)$ had no radiological findings of relevance to treatment.

Conclusions The choice of radiographic examination for the majority of patients in the study did not follow current guidelines. Dentists diagnosed fewer abnormalities than did experts. While many radiological findings are revealed by panoramic radiography, these may either duplicate information from bitewing radiographs or are often of no significance to treatment planning. This study did not provide evidence to support the practice of routine panoramic radiography of all new adult patients.
\end{abstract}

The proliferation of panoramic radiography in general dental 1 practice in the United Kingdom over the last two decades has been remarkable, rising from 0.7 million in 1981 to 2.04 million in

${ }_{1}^{1}$ Lecturer in Dental and Maxillofacial Radiology, ${ }^{2}$ Senior Lecturer in Dental and Maxillofacial Radiology, ${ }^{3}$ Reader in Dental Statistics, Department of Dental Medicine and Surgery, University Dental Hospital of Manchester, Higher Cambridge Street, Manchester M15 6FH

Correspondence to: DrVE Rushton

email:vivian.e.rushton@man.ac.uk

REFEREED PAPER

Received 05.06.00; Accepted 09.11.00

(C) British Dental Journal 2001; 190: 495-501
1998/9. ${ }^{1}$ In 1994, the National Radiological Protection Board estimated that there were 3,250 panoramic $\mathrm{x}$-ray sets in use in the United Kingdom. ${ }^{2}$

It is a fundamental requirement of radiation protection that all exposures to $\mathrm{X}$-rays as part of diagnosis should be clinically justified for each patient. ${ }^{3}$ Nevertheless, a recent questionnaire study ${ }^{4}$ found that $42 \%$ of dentists with panoramic $x$-ray equipment carried out routine panoramic radiography of all new adult patients. This practice of 'screening' has been condemned in recent evidence-based guidelines. ${ }^{5}$ In order to justify routine panoramic screening, it would be necessary to demonstrate a significant diagnostic yield that outweighed the risks of the $\mathrm{x}$-ray exposure.

A number of studies, reviewed by Rushton and Horner, have measured the diagnostic yield obtained from panoramic radiology. ${ }^{6}$ However, these studies were not performed in general dental practice, instead they were surveys of hospital patients or of specific target groups of individuals. Furthermore, these previous studies have recorded all radiological findings, regardless of whether they were of clinical significance or whether they would have been identified on posterior bitewing radiography. The latter is recommended ${ }^{5}$ as an essential aid to diagnosis in initial examination of dentate patients and, in such instances, panoramic radiography may simply duplicate diagnostic yield already available to the dentist.

The aim of this study was to identify the radiological findings from routine screening panoramic radiographs taken of adult (18 years and over) patients in general dental practice, taking into account the findings that would have been identified on posterior bitewing radiographs and the relevance to treatment of the findings.

\section{Materials and methods}

In 1997, a questionnaire-based study was performed which addressed various aspects of panoramic radiography in general dental practice. The study, previously reported, ${ }^{4,7}$ received completed questionnaires from 542 dentists (73.3\% response rate). Forty-two per cent of respondents identified themselves as always taking a panoramic radiograph of new adult ( $\geq 18$ years) patients. To these practitioners, a letter was sent inviting them to participate in a prospective study on panoramic radiography.

A total of 41 dentists agreed to take part in the study, which commenced in the autumn of 1998 and concluded in the late winter of 1999. Each dentist was asked to provide, prospectively, the panoramic radiographs of 50 consecutive new adult ( $>18$ years) patients. In addition, the dentists were asked to include a radiological report ('dentist assessment') for the panoramic radiograph of each patient. Details of the checklist given to the dentists for the purposes of the radiological report are given in Table 1. The radiological findings from the panoramic radiographs is subsequently described here as the Radiological Yield (RY).

Finally, the dentists were required to provide basic patient information and give details of their proposed treatment plan for each patient. Each plan was submitted to the investigators, along with the 
associated panoramic radiograph and radiological report. In each case, dentists were asked to record whether they had taken any other radiographs of their patient and, when a positive response was given, what type of radiograph had been taken. They were also asked to record, for each patient, the radiographs they would have taken if they had no panoramic facility in their practice.

Upon receipt, each radiograph was viewed simultaneously by two dental radiologists (VER and $\mathrm{KH}$ ) and a consensus radiological report prepared ('expert assessment') using the checklist in Table 1.

\section{Modified Radiological Yield (MRY)}

For each patient's radiograph, the 'expert' list of radiological findings was modified by exclusion of those findings that would have been identified on posterior bitewing radiographs. This was defined as the Modified Radiological Yield (MRY) for each patient. It was assumed that, for dentate patients, any lesion in the posterior premolar/molar regions corresponding in area to a size $2(3$ by $4 \mathrm{~cm}$ ) intraoral film would have been identified by bitewing radiography. All carious lesions in these regions were therefore excluded from analysis, as was periodontal bone loss and presence of calculus deposits. The precise area on the panoramic radiographs covered by right and left posterior bitewing radiographs was that defined by Whaites. ${ }^{8}$ For edentulous patients, where bitewing radiography was not applicable, this modification was not performed and MRY was identical to RY. For partially dentate patients the 'expert' investigators made individualised patient judgements about whether bitewing radiography would have been practicable on one, or both, sides of the mouth and RY modified appropriately.

\section{Modified Radiological Yield of Relevance to Treatment (MRYT)}

The 'expert' MRY was then re-assessed by the investigators in conjunction with the proposed treatment plan supplied by the dentists. For each radiograph, the radiological findings contributing to MRY were modified by the exclusion of all those findings of no relevance to treatment (purely documentary findings). A radiological finding was considered to be 'documentary' and of no relevance to treatment where: (i) its discovery had not influenced (either positively or negatively) the treatment plan of the dentist, and (ii) where it did not, in the consensus opinion of the investigators, require treatment or justify further clinical and/or radiological review. Two new categories of radiological finding were, however, included in the assessment: 'preextraction information' and 'significant negative finding. For the former, the radiograph was judged to have been useful where radiography is widely accepted as being appropriate prior to certain types of dental extraction (ie for third molars and lone-standing upper molar teeth). A 'significant negative finding' was recorded in those instances where it was judged that the radiograph had been taken prudently to exclude significant pathology, such as a bony fracture. The new measures of radiological yield were termed MRYT.

\section{Statistical analyses}

The radiological findings at the four levels of assessments (Dentist RY, Expert RY, MRY and MRYT) were recorded on a spreadsheet for analysis.

The ages of the patients in the study were compared using a goodness of fit Chi-square test with data obtained from the Dental Practice Board of England and Wales ${ }^{9}$ (DPB) on the age distribution of a $5.5 \%$ sample of all patients who underwent panoramic radiographic examination in the year 1998/99.

An estimation of agreement between 'dentists' and 'expert' radiological assessments was made by determination of percentage agreement for presence or absence of each of the radiological findings listed in Table 1. A comparison between 'dentists' and 'expert' assessments for proportions of cases with and without a positive radiological finding was made using $\mathrm{McNemar} \mathrm{X}^{2}$ tests.

A random sample of 125 radiographs (6.9\%) was retrieved and re-assessed by the experts. The resulting data was related to that from the original assessment (expert RY) using 2 by 2 tables relating presence/absence for each of the radiological findings in Table 1. A measure of agreement between the repeated assessments was made by calculation of the kappa statistic. ${ }^{10}$ A further random sample of 50 radiographs $(2.7 \%)$ was retrieved and each independently assessed by the two experts in isolation. Inter-expert agreement was also measured by calculation of the kappa statistic.

\section{Results}

The 41 dentists submitted a total of 1,818 panoramic radiographs for the study. Only 28 of the dentists returned a complete allocation of 50 radiographs and completed proformas, the remaining dentists having submitted less than 50 before time and financial constraints necessitated the termination of the study.

The patients ranged in age from 18 to 84 years (mean age 37.9 years). The proportions of patients in the study, divided into age bands, are shown in Figure 1 and compared with the DPB sample of all patients for whom a panoramic radiograph was scheduled during the year 1998/99. There was no significant difference in age profile between the study sample and the DPB population figures $(P=0.26)$. Males made up $51.5 \%$ of the patients. The year in which the patients had last attended a dentist for routine care ranged from 1972 to 1998 , with the majority $(68.2 \%)$ having received dental care in the previous 4 years (1995-98).

No radiographs other than the panoramic radiograph had been taken for $57.1 \%$ of patients. In the cases where other films had been exposed, bitewings, periapicals or combinations of these had been used in all but $0.4 \%$. When dentists were asked what radiographs they would have taken in the absence of a panoramic facility in the practice, for $32.4 \%$ of patients they stated they would have used bitewing and periapical radiographs, for $30.8 \%$ periapical radiographs and for $27.1 \%$ bitewing radiographs. For $2.3 \%$ of patients no radiography would have been performed.

\section{Radiological Yield (RY)}

The radiological findings recorded by the GDPs and the experts, along with the percentage agreement between the two assessments, are summarised in Table 2. One radiograph was returned to the dentist without expert assessment and could not be retrieved, so the number of films assessed by the experts was 1,817 . For the dentist assessments, only $4.6 \%$ of patients had radiographs with no radio-

\section{Table I Information recorded for each patient based on interpretation of the panoramic radiograph only}

Presence of calculus deposits Yes/No

Periodontal bone loss Early (up to one third loss of bone attachment)

Moderate (one to two thirds loss of bone attachment)

Advanced (more than two thirds loss of bone attachment)

Caries Number of teeth with lesions present

Periapical inflammatory Number of teeth with lesions present

pathology

\begin{tabular}{ll} 
Retained roots & Number of roots* \\
\hline Unerupted teeth & Yes/No
\end{tabular}

\begin{tabular}{ll}
$\begin{array}{l}\text { Pathology affecting one/both of } \\
\text { the maxillary antra }\end{array}$ & Yes/No \\
\hline Other abnormalities & Yes/No; specific details recorded
\end{tabular}

Other abnormalities

Yes/No; specific details recorded

*To avoid confusion, dentists were asked to record the number of units (teeth) where roots were retained eg two retained roots of a lower molar were recorded as one retained root in the report 


\begin{tabular}{|c|c|c|c|c|}
\hline & $\begin{array}{c}\text { Dentist } \\
\text { assessment } \\
\text { Number (\%) }\end{array}$ & $\begin{array}{c}\text { Expert } \\
\text { assessment } \\
\text { Number (\%) }\end{array}$ & $\begin{array}{c}\% \\
\text { agreement }\end{array}$ & $P$ \\
\hline Presence of calculus deposits & $849(46.7)$ & $961 \quad(52.9)$ & 70.5 & $<0.001$ \\
\hline \multicolumn{5}{|l|}{ Periodontal bone loss } \\
\hline None & $530(29.2)$ & 785 (43.2) & 52.0 & $<0.001$ \\
\hline Early & $673(37.0)$ & $682(37.5)$ & & \\
\hline Moderate & $436(24.0)$ & $297(16.3)$ & & \\
\hline Advanced & $179(9.8)$ & $53 \quad(3.0)$ & & \\
\hline Total with bone loss & $1288(70.8)$ & $1032(56.8)$ & & \\
\hline \multicolumn{5}{|l|}{ Number of carious lesions } \\
\hline None & $783(43.1)$ & $560(30.8)$ & 37.1 & $<0.001$ \\
\hline I & $386(21.2)$ & $359(19.7)$ & & \\
\hline 2 & $219(12.1)$ & $290(16.0)$ & & \\
\hline 3 & $151 \quad(8.3)$ & $182(10.0)$ & & \\
\hline 4 & $100 \quad(5.5)$ & $127 \quad(7.0)$ & & \\
\hline 5 or more & $179(9.8)$ & $299(16.5)$ & & \\
\hline Total with any lesions & $1035(56.9)$ & $1257(69.2)$ & & \\
\hline \multicolumn{5}{|l|}{ Number of periapical lesions } \\
\hline None & $|26|(69.3)$ & $1087(59.8)$ & 69.9 & $<0.001$ \\
\hline I & $367(20.2)$ & $420(23.1)$ & & \\
\hline 2 & $130(7.1)$ & $162 \quad(8.9)$ & & \\
\hline 3 & $30 \quad(1.7)$ & $78 \quad(4.3)$ & & \\
\hline 4 or more & $30 \quad(1.7)$ & $70 \quad(3.9)$ & & \\
\hline Total with any lesions & $557(30.7)$ & $730(40.2)$ & & \\
\hline \multicolumn{5}{|l|}{ Number of retained roots } \\
\hline None & I586 (87.2) & $1503(82.7)$ & 91.3 & $<0.001$ \\
\hline 1 & $169 \quad(9.3)$ & $230(12.7)$ & & \\
\hline 2 & $33 \quad(1.8)$ & $45 \quad(2.5)$ & & \\
\hline 3 or more & $30 \quad(1.8)$ & $39 \quad(2.1)$ & & \\
\hline Total with any retained roots & $232(12.8)$ & $314(17.3)$ & & \\
\hline Presence of unerupted teeth & $623(34.3)$ & $647(35.6)$ & 95.1 & 0.01 \\
\hline Pathology of maxillary antra & II (0.6) & $255(14.0)$ & 86.7 & $<0.001$ \\
\hline Other abnormalities & $64 \quad(3.5)$ & $366(20.1)$ & 80.0 & $<0.001$ \\
\hline
\end{tabular}

logical findings, while for the expert assessment this proportion was just $3.1 \%$. With the exception of the assessment of periodontal bone loss, the experts diagnosed significantly greater proportions of cases as having positive radiological findings. Agreement between dentist and expert assessments varied greatly. For some findings such as 'retained roots' and 'unerupted teeth', agreement was high (>90\%). In contrast, agreement was notably poor (37.1\%) for caries diagnosis. In the case of periodontal bone loss, dentists diagnosed a significantly greater proportion of cases as having this finding and agreement with the expert assessment was, unsurprisingly, low (52\%). Furthermore, dentists included greater proportions of cases as having moderate or advanced bone loss. Of the 'other abnormalities', dentists identified 64 cases, considerably fewer than the experts. Of these 64, there were 13 cases where there was no agreement with the experts. These included ten 'radiolucent areas' or 'cysts' that, in the experts' opinion, were normal trabecular pattern, artefactual air shadows or normal anatomy (mental foramen), A breakdown of the 'other abnormalities' identified by the dentists $(n=64)$ and experts $(n=366)$ is given in Table 3.

The majority of patients were dentate $(1,112 ; 61.2 \%)$, with 697 $(38.3 \%)$ partially dentate individuals but with only $9(0.5 \%)$ edentulous patients.

Repeatability of 'expert' radiological assessments is shown in
Table 4. As numbers of cases with pathology within the maxillary antra and 'other' abnormalities were both few, these categories of radiological finding were combined. According to Landis and Koch, ${ }^{11}$ values of kappa exceeding 0.75 indicate excellent agreement beyond chance, values between 0.4 and 0.75 indicate fair to good agreement beyond chance, while values below 0.4 indicate poor agreement. Agreement between repeated assessments by the two experts was excellent for all types of pathologies considered except for 'presence of calculus' and 'numbers of carious lesions' where agreement was only 'fair to good'. In the case of inter-expert agreement, levels of kappa were excellent for all categories except 'other abnormalities'.

\section{Modified Radiological Yield (MRY)}

As this assessment was based upon the expert viewing of the radiographs, the total number of cases included was 1,817. The radiological findings contributing to MDY are detailed in Table 5. No radiological findings were recorded on the radiographs of $17.2 \%$ of patients.

Modified Radiological Yield of Relevance to Treatment (MRYT) For one case the dentist gave no treatment plan so the number of cases included in this level of assessment was 1,816 . The radiological 
Table 3 'Other abnormalities' identified by the dentists and the experts on the panoramic radiographs of the study patients $(n=1818$ for dentists; $n=1,817$ for experts)

\begin{tabular}{|c|c|c|c|}
\hline & Abnormality & $\begin{array}{c}\text { Expert } \\
\text { assessment } \\
n=366\end{array}$ & $\begin{array}{c}\text { Dentist } \\
\text { assessment } \\
n=64\end{array}$ \\
\hline Dental & $\begin{array}{l}\text { External root resorption } \\
\text { Supernumerary teeth } \\
\text { Hypodontia } \\
\text { Signs of chronic pericoronal infection } \\
\text { Retained deciduous teeth } \\
\text { Hypercementosis } \\
\text { Root perforation } \\
\text { Odontomes } \\
\text { Other }\end{array}$ & $\begin{array}{r}27 \\
17 \\
11 \\
8 \\
6 \\
4 \\
3 \\
2 \\
10\end{array}$ & $\begin{array}{r}17 \\
3 \\
2 \\
0 \\
2 \\
0 \\
1 \\
1 \\
5\end{array}$ \\
\hline 'Cystic' & $\begin{array}{l}\text { Enlarged follicle/dentigerous cyst } \\
\text { Radicular/residual cyst } \\
\text { Stafne bone cavity } \\
\text { ?keratocyst } \\
\text { Other }\end{array}$ & $\begin{array}{r}11 \\
10 \\
4 \\
1 \\
0\end{array}$ & $\begin{array}{r}6 \\
1 \\
0 \\
1 \\
10\end{array}$ \\
\hline Other jaw & $\begin{array}{l}\text { Idiopathic osteosclerosis } \\
\text { Ossified stylohyoid ligament } \\
\text { Osteopenia/osteoporosis } \\
\text { Surgical wires/plates } \\
\text { Other }\end{array}$ & $\begin{array}{r}40 \\
26 \\
21 \\
6 \\
9\end{array}$ & $\begin{array}{l}5 \\
1 \\
0 \\
1 \\
1\end{array}$ \\
\hline TMJ & $\begin{array}{l}\text { Osteoarthrosis } \\
\text { 'Bifid' condyle } \\
\text { Hypoplastic condyle } \\
\text { Other }\end{array}$ & $\begin{array}{r}43 \\
8 \\
7 \\
9\end{array}$ & $\begin{array}{l}0 \\
0 \\
0 \\
0\end{array}$ \\
\hline $\begin{array}{l}\text { Soft tissue } \\
\text { calcification }\end{array}$ & $\begin{array}{l}\text { Tonsils } \\
\text { Carotid artery } \\
\text { Larynx } \\
\text { Lymph node } \\
\text { Salivary calculus } \\
\text { Other }\end{array}$ & $\begin{array}{r}52 \\
9 \\
7 \\
6 \\
5 \\
4\end{array}$ & $\begin{array}{l}6 \\
0 \\
0 \\
0 \\
1 \\
0\end{array}$ \\
\hline
\end{tabular}

findings contributing to MDYT are detailed in Table 6. The majority of radiographs (56.3\%) had no radiological findings of relevance to treatment. The 'other abnormalities' category consisted of many different findings, but the commonest of these were 'cysts' (20 radiographs) and external resorption of teeth (6 cases).

The relative proportions of radiographs showing a radiological diagnostic yield at each of the three levels of assessment by the experts are illustrated by Figure 2. This combines the findings detailed in Tables 2, 5 and 6 after exclusion of calculus and periodontal bone loss (only considered at the RY level).

\section{Discussion}

This study had the aim of recording the radiological findings from 'screening' panoramic radiography of adult. In the context of this study, 'screening' was defined as routinely taking a panoramic radiograph of any new adult (18 years or older) patient, regardless of the presence or absence of symptoms or signs at presentation. For the results to be valuable, it was essential that the patients within the study should depict an accurate and representative sample of all those adult patients undergoing panoramic radiography in general dental practice in England and Wales. Evidence that the sample was representative was confirmed by comparison with DPB data (Fig. 1). ${ }^{9}$ This showed that the greatest numbers of panoramic radiographs are taken in the younger age groups. Any use of ionising radiation should take into account the risks and the benefits. Risks from exposure to ionising radiation are higher for younger patients and thus the benefits, particularly when 'screening' patients, should be clearly demonstrable.

All the dentists recruited to the study had previously identified themselves as practising 'routine' panoramic radiography of all new
Table 4 Repeatability of 'expert' radiological assessments. Values for the kappa statistic are shown with $95 \%$ confidence intervals $(\mathrm{Cl})$. 'All other abnormalities' combined 'pathology in the maxillary antra' and 'other abnormalities' referred to in Table I

\begin{tabular}{|c|c|c|}
\hline & $\begin{array}{l}\text { Inter-assessment } \\
\text { repeatability: } \\
\text { kappa }(95 \% \mathrm{Cl})\end{array}$ & $\begin{array}{l}\text { Inter-expert } \\
\text { repeatability: } \\
\text { kappa }(95 \% \mathrm{Cl})\end{array}$ \\
\hline Presence of calculus deposits & $0.60(0.46,0.74)$ & $0.88(0.74,1.00)$ \\
\hline Periodontal bone loss & $0.87(0.81,0.92)$ & $0.89(0.81,0.96)$ \\
\hline $\begin{array}{l}\text { Number of teeth with carious lesions } \\
\text { Number of teeth with periapical }\end{array}$ & $0.55(0.40,0.70)$ & $0.86(0.82,0.90)$ \\
\hline inflammatory lesions & $0.82(0.74,0.91)$ & $0.78(0.65,0.91)$ \\
\hline Number of retained roots & $0.79(0.66,0.91)$ & 1.00 \\
\hline Presence of unerupted teeth & $0.94(0.87,1.00)$ & 1.00 \\
\hline All other abnormalities & $0.84(0.74,0.94)$ & $0.64(0.43,0.85)$ \\
\hline
\end{tabular}

adult patients, thereby eliminating any bias upon the results by inter-practitioner variation in choosing which patients would receive a panoramic examination. Whilst it is impossible to be completely sure that the 41 participating dentists were representative of their peers, the method adopted for the selection and recruitment of the participants was a pragmatic approach taking into account the geographical variation in dentist and patient profiles. Clearly, a more representative sample would have been possible only by compulsory involvement of a random sample of all dentists in England and Wales, an option that was not available in this study.

The numbers of dentists and patients included in the study were limited solely by financial constraints, whilst time limitations on the

Table 5 Radiological findings on the I,8I7 panoramic radiographs after exclusion of information that would have been identified on posterior bitewing radiographs

Number (\%)

\begin{tabular}{|c|c|c|}
\hline \multicolumn{3}{|l|}{ Number of carious lesions } \\
\hline None & $|40|$ & $(77.1)$ \\
\hline I & 243 & $(13.4)$ \\
\hline 2 & 96 & $(5.3)$ \\
\hline 3 & 38 & (2.1) \\
\hline 4 & 20 & (I.I) \\
\hline 5 or more & 19 & $(1.0)$ \\
\hline Total with any lesions & 406 & $(22.9)$ \\
\hline \multicolumn{3}{|l|}{ Number of periapical lesions } \\
\hline None & 1087 & $(59.8)$ \\
\hline I & 420 & $(23.1)$ \\
\hline 2 & 162 & (8.9) \\
\hline 3 & 78 & $(4.3)$ \\
\hline 4 or more & 70 & (3.9) \\
\hline Total with any lesions & 730 & $(40.2)$ \\
\hline \multicolumn{3}{|l|}{ Number of retained roots } \\
\hline None & 1503 & $(82.7)$ \\
\hline I & 230 & $(12.7)$ \\
\hline 2 & 45 & $(2.5)$ \\
\hline 3 or more & 39 & $(2.1)$ \\
\hline Total with any retained roots & 314 & $(17.3)$ \\
\hline \multicolumn{3}{|l|}{ Presence of unerupted teeth } \\
\hline None & 1170 & $(64.4)$ \\
\hline I or more & 647 & $(35.6)$ \\
\hline \multicolumn{3}{|l|}{ Pathology of maxillary antra } \\
\hline None & 1562 & $(86)$ \\
\hline Either or both antra & 255 & (14) \\
\hline \multicolumn{3}{|l|}{ Other abnormalities } \\
\hline None & $|45|$ & $(80)$ \\
\hline I or more & 366 & (20) \\
\hline
\end{tabular}




\begin{tabular}{|c|c|}
\hline & $\begin{array}{c}\text { Number of } \\
\text { radiographs (\%) }\end{array}$ \\
\hline \multicolumn{2}{|l|}{ Number of carious lesions } \\
\hline None & 1567 (86.2) \\
\hline I & $147 \quad(8.1)$ \\
\hline 2 & $53 \quad(2.9)$ \\
\hline 3 & $23 \quad(I .3)$ \\
\hline 4 & II $(0.6)$ \\
\hline 5 or more & $15 \quad(0.8)$ \\
\hline Total with any lesions & $249(13.8)$ \\
\hline \multicolumn{2}{|l|}{ Number of periapical lesions } \\
\hline None & 1406 (77.4) \\
\hline I & $291(16.0)$ \\
\hline 2 & $85 \quad(4.7)$ \\
\hline 3 & $15 \quad(0.8)$ \\
\hline 4 or more & $19 \quad(1.1)$ \\
\hline Total with any lesions & $410(22.6)$ \\
\hline \multicolumn{2}{|l|}{ Number of retained roots } \\
\hline None & I68I (92.6) \\
\hline 1 & $94 \quad(5.2)$ \\
\hline 2 & $15 \quad(0.8)$ \\
\hline 3 or more & $26 \quad(1.4)$ \\
\hline Total with any retained roots & $135 \quad(7.4)$ \\
\hline Presence of unerupted teeth & $156 \quad(8.6)$ \\
\hline Pathology of maxillary antra & $5 \quad(0.3)$ \\
\hline Other abnormalities & $69 \quad(3.8)$ \\
\hline Pre-extraction information & $189(10.4)$ \\
\hline Significant negative finding & $2(0.1)$ \\
\hline
\end{tabular}

duration of the study meant that some dentists did not complete their full potential allocation of 50 cases. This may have led to bias in diagnostic yield as, for example, in those cases were the participating dentist practised in an area with higher levels of dental disease and would, therefore, presumably encounter little difficulty in completing 50 cases. However, communication with the dentists showed that the slow return of cases from some participants was entirely related to the recruitment of new patients to their practices, a factor outside the control of both the dentists and those involved in the study.

This study only considered the adult patient. The influence of orthodontic treatment on panoramic radiographic prescription, largely absent from the adult group, is so marked that it was considered inappropriate to include children. Previous workers, reviewed by Rushton and Horner have addressed the child patient solely from the standpoint of the use of panoramic radiography in orthodontic diagnosis. ${ }^{6}$ It was, therefore, considered inappropriate to combine adult and child patients in one study. As the study sample mirrored the age profile of the DPB population there was, as already discussed, an age bias towards younger adults. It is important to remember, however, that a more balanced age profile, with equal numbers in all age bands, might have led to differences in overall radiological yield. Thus, further work would be appropriate if there was a specific need to examine patients in a target age band, particularly if that band were in the older age ranges.

The proportion of patients in this study that was edentulous was small $(0.5 \%)$, contrasting with an estimated level of $13 \%$ found following a recent survey of adult dental health in the United King- dom. ${ }^{12}$ The figure of $0.5 \%$ seen here is likely to reflect the infrequency of attendance for routine dental check-ups by this group. This pattern of non-attendance has been previously noted, ${ }^{12}$ with one half of edentulous patients stating that they had not attended the dentist for more than 10 years.

It was striking that for over $57 \%$ of patients in this study, no radiographs other than the panoramic film were taken. This agrees generally with the findings of previous research by Osman et al., ${ }^{13}$ suggesting that attitudes towards the diagnostic value of panoramic radiography for the diagnosis of everyday dental diseases (caries, periapical pathology and periodontal bone loss) have not altered in the intervening years. The questionnaire survey of dentists carried out prior to this study ${ }^{7}$ showed, however, that the majority of dentists recognised the deficiencies of the panoramic technique in the diagnosis of common dental pathosis. Such a paradox is difficult to explain, although one could infer that the participating dentists in this study might be representative of the minority of practitioners who do not understand or accept the inferior diagnostic value of panoramic radiography. Alternatively, it may be that either the monetary rewards of panoramic radiography relative to those for intraoral techniques, or the fact that panoramic radiography can be easily and frequently delegated to other members of the dental team, outweigh their obvious diagnostic inferiority for some dentists.

Numerous studies, reviewed previously, ${ }^{6}$ have demonstrated the inferiority of panoramic radiographs for the radiographic diagnosis of common dental pathology. Regardless of the reasons for choosing to take only a panoramic film, this study suggests that there is an urgent need for instituting a concerted educational programme to change these radiological practices and that this incentive should rapidly be instigated for the sake of quality of patient care. This is particularly pertinent when the profile of evidence-based practice is so high within clinical governance. Those in authority, the Department of Health, the Dental Practice Board and other third party payment institutions, need to be active in the development of such a programme.

Many of the radiographs included in the study (33\%) were of limited diagnostic quality. We could have chosen to exclude these from analysis, but made a decision not to do so because the dentists involved in the study had clearly not chosen to repeat the radiogra-

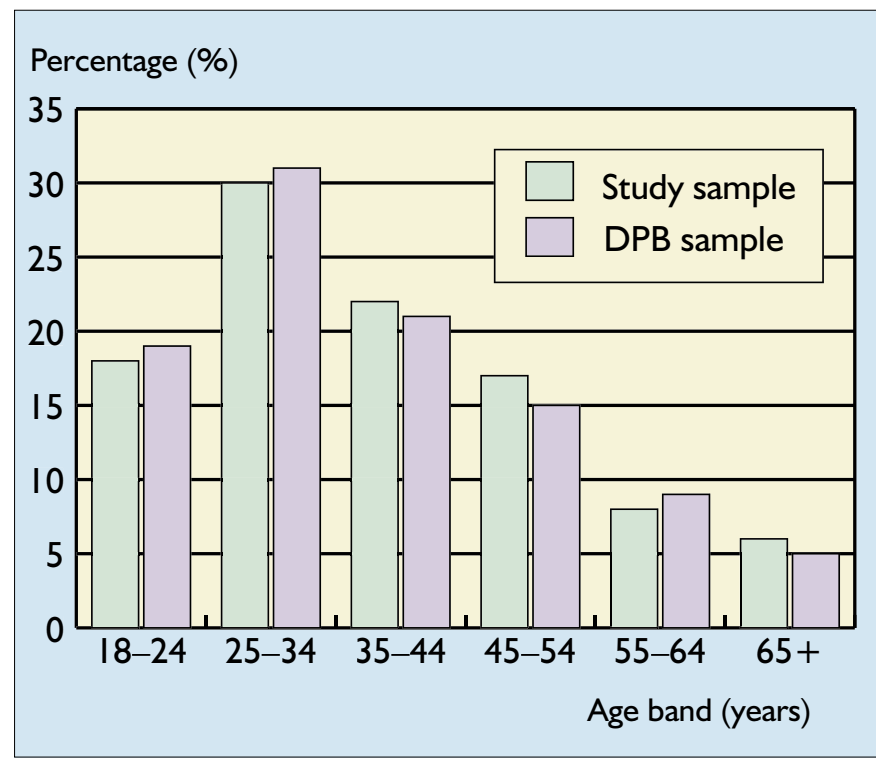

Fig. I The numbers and proportions of patients in the study, compared with Dental Practice Board (DPB) figures. 9 Data on age of patients in the study was missing in 13 cases, so the study sample here was $I, 805$. The DPB data was a sample $(n=7 I, 268)$ of $5.5 \%$ of all patients for whom item of service claims were scheduled during the year ending March 1999 
phy. Thus we felt that to include poor quality films only reflected the 'real world' situation rather than an ideal one. Inevitably, to include poor quality films means that some radiological findings that may have been present were not recorded.

This study is the first to examine diagnostic yield from the entire adult range of new patients in a British general dental practice setting. Most studies measuring radiological findings on panoramic radiographs have been based upon target groups such as armed forces personnel or hospital patients with specific referral criteria. Consequently, comparison of the radiological findings of this study with those previously carried out is of limited value.

Inevitably, this study can be criticised for recording pathoses and anomalies from radiographs that have recognised limitations in diagnostic validity (sensitivity and specificity) for the common dental diseases such as caries and periapical pathosis. It is important to recognise that no 'gold standard' diagnosis is possible in a clinical study of this nature, so that it is impossible to know the proportions of assessments made by observers that were false positives or negatives. Nevertheless, the radiographs represented real patients and the uncertainty over accuracy of diagnosis is something that dentists have to cope with every day. In addition to this problem, a second factor of importance was observer variation in reading the radiographs.

It could be argued that inclusion of symptomatic patients in the study involved a group of individuals for whom the panoramic examination was not, strictly, a 'screening' procedure. However, this argument erroneously assumes that any symptom would have justified the panoramic examination. Certainly, there must have been a proportion of symptomatic patients for whom a panoramic radiograph was a reasonable investigation eg prior to lower third molar surgery. Nevertheless, most of the symptomatic patients had 'toothache' in a single tooth that would have most properly been radiographed by an intra-oral technique. It was not possible to remove the small proportion of patients for whom a panoramic radiograph may have been justified from the study sample as the information needed to assess justification was not collected in the clinical proforma. If it had been possible to do so, the likely consequences would have been that the remaining sample would have shown fewer radiological findings of relevance to treatment.

Table 2 shows significant differences between the dentists and the expert assessments. Inter-observer variation in radiological diagnosis is a well-recognised and important aspect of clinical dentistry. ${ }^{14-18}$ Nevertheless, there was a clear tendency for the expert assessment to identify greater numbers of patients with abnormality, with the exception of periodontal bone loss. Furthermore, percentage agreement in identification of caries was particularly low (37.1\%). If it is accepted that 'experts' can do their specialised job better than general dentists, ${ }^{19,20}$ this study shows that abnormalities were not identified by practitioners when present. This fact underscores the need to use the diagnostically more valid intraoral radiographic techniques in everyday clinical practice. The apparent over-diagnosis of periodontal bone loss by dentists was, however, entirely unexpected. The definitions of early, moderate and advanced periodontal bone loss were explained to the participating dentists before the study started. Perhaps the dentists did not recognise the 'normal' periodontal bone level at 1 to $1.5 \mathrm{~mm}$ below the amelo-cemental junction ${ }^{21}$ and therefore diagnose more people as having early bone loss. If so, this does not explain the greater numbers of patients diagnosed with moderate or advanced bone loss. The results of this study have demonstrated that more emphasis needs to be placed on radiological diagnosis in basic undergraduate dental education and in courses for qualified dentists.

The incidence of unerupted teeth (35.6\% of patients in the expert assessment) is considerably higher than the $13.3 \%$ reported by Stephens et al. ${ }^{22}$ in a synopsis of fourteen previously published studies containing the results of 34,421 radiographic surveys. How-
Percentage (\%)

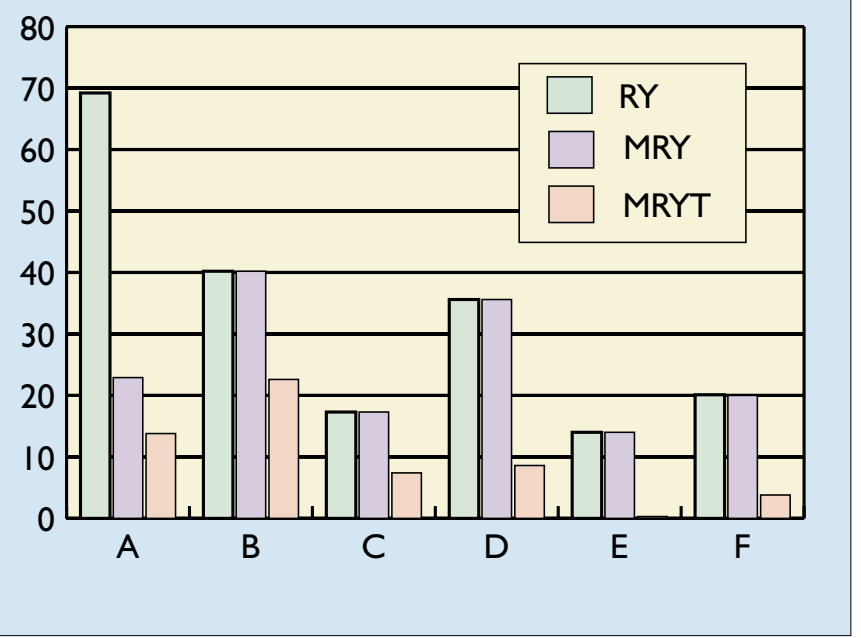

Fig. 2 The proportions (\%) of radiographs in the study identified by the expert assessment as showing abnormalities at the RY, MRY and MRYT levels. Calculus and periodontal bone loss are not included as these were only included at the $R Y$ level. A = carious lesions, $B=$ periapical lesions, $C=$ retained roots, $D=$ unerupted teeth, $\mathrm{E}=$ maxillary antral pathology, $\mathrm{F}=$ other abnormalities

ever, this difference can be explained: the reviewed studies $^{22}$ were biased towards surveys of edentulous patients while the current study contained few edentulous individuals.

Much of this study was based upon the 'expert' radiological assessments. The recognised variation in diagnosis, even amongst experts, meant that a consensus assessment of two dental radiologists was chosen on the grounds that this has previously been shown to improve repeatability. ${ }^{23,24}$ For inter-assessment repeatability, in all respects except two (presence of calculus and number of teeth with caries), agreement of experts with themselves (Table 4) was excellent. In the cases of the two exceptions, where agreement was only 'fair to good', the inferior performance of the experts is readily explained. Calculus has low radiopacity, is largely superimposed on teeth of greater radiopacity and may be found on only one or on many sites in the mouth. Thus making the same diagnosis twice is more difficult than in the case of, for example, the presence of unerupted teeth. In the case of caries, the relatively low agreement $($ kappa $=0.55)$ simply reflects the limitations of the panoramic technique for this exacting diagnostic task. It is likely that if caries had been recorded by observers at the D3 threshold (ie in dentine), dentist/expert agreement and repeatability of expert assessments would have been higher. However, the fact that a high number of patients had no bitewing radiographs taken indicated that all caries should be included in the assessment. The assessment of interexpert agreement (Table 4) also showed high levels of agreement, indicating a high level of concordance in diagnosis from panoramic radiographs and arguing against the view that one expert may have been 'dominant' over the other.

Comparison of Table 2 with Table 5 demonstrates the considerable reduction in numbers of radiological findings from panoramic radiographs when those findings that would be identified on posterior bitewing films were excluded. This is not surprising. Inevitably, bearing in mind relative disease prevalences, the exclusion of caries in posterior teeth and of periodontal bone loss from radiological yield, both common diseases, was likely to have a dramatic effect. This echoes the work of White et al. ${ }^{25}$ who found that panoramic radiography was least productive in dentate patients where intra-oral radiographs were already available. It might be argued that exclusion of periodontal bone loss from MRY was harsh when posterior 
bitewings do not demonstrate bone levels in the anterior segments of the mouth. However, it seemed reasonable to presume that a dentist, alerted by bone loss on bitewing films, would conduct a clinical periodontal examination of other regions and, if needed, perform selected periapical radiographs where bone loss was irregular.

Examination of Table 6 in parallel with Tables 2 and 5 demonstrates the dramatically lower numbers of radiological findings that were of relevance to treatment. The originally high proportion of patients with unerupted teeth $(35.6 \%)$ can be compared with the $8.6 \%$ for whom the finding had some clinical impact. The magnitude of this proportion might itself be considered as an overestimate in view of evidence that dental practitioners frequently exaggerate the potential of unerupted teeth to develop pathology. ${ }^{26}$ Furthermore, clinical guidelines produced after the completion of this study ${ }^{27}$ might also have lowered MRYT. In a similar manner, it is possible to see the very small number of patients who had a significant abnormality of the maxillary antrum, despite an 'abnormality' being present in $14 \%$ of the patients. This pattern of screening radiography uncovering irrelevant 'pathology' has been reported previously; Barrett et al. ${ }^{28}$ in their survey of panoramic radiographs, found 200 instances of pathosis in 167 patients but in only 12 individuals was any treatment indicated. Similar findings were reported for a sample of periodontal clinic patients by Osbourne and Hemmings. ${ }^{29}$

These factors contributed to the fact that, after removal of findings identifiable on posterior bitewings and findings of no treatment relevance, $56.3 \%$ of patients had no radiological yield at all. This is of major importance in judging the validity of using panoramic radiology as a screening procedure in general dental practice. The results, showing that most patients have no diagnostic benefit whatsoever, add important weight to previous condemnation of screening radiography.

Previous research suggests that the application of selection criteria for intraoral radiography could effectively remove any perceived need for panoramic radiography. Akerblom et al..$^{30}$ showed that taking periapical radiographs of teeth with clinical signs and symptoms, and of those with endodontic treatment or deep caries as identified on bitewing radiographs, revealed $90 \%$ of periradicular lesions. Brooks and $\mathrm{Cho}^{31}$ reported similar findings. Both Brooks ${ }^{32}$ and Richardson ${ }^{33}$ have carried out studies using clinically based selection criteria for periapical radiography and shown that 'missed findings' identifiable solely by panoramic radiography could be reduced to a few anomalies and pathoses of questionable clinical significance.

Inevitably, the use of radiographic selection criteria involves a trade-off between reducing unnecessary radiological examinations at the expense of missing a small number of lesions without signs or symptoms that would otherwise have indicated radiography. Routine screening panoramic examinations cost patients and/or the National Health Service significant amounts of money and a radiation risk to the patient. Thus, the onus should be on the proponents of screening to justify these costs in the light of the evidence that only a few, mainly innocuous, findings would be missed by selected radiography. The results of this study add considerable weight to the argument that screening panoramic radiology is unjustifiable in general dental practice. Further analysis of the data to identify clinical indicators of a high diagnostic yield will be reported in the future.

This study was supported by a grant from the NHS North West Regional reactive funding scheme. We thank Annette Vesty for inputting all the data and the general dental practitioners for participating in the study.

1 Dental Practice Board. Personal Communication. Dental Data Services, Dental Practice Board for England and Wales, 1999.

2 Royal College of Radiologists and National Radiological Protection Board. Guidelines on Radiological Standards for Primary Dental Care. Vol. 5. No. 3. Chilton: National Radiological Protection Board, 1994.
3 International Commission on Radiological Protection. ICRP Publication 60. Radiation Protection. 1990 recommendations of the International Commission on Radiological Protection. Annals of the International Commission on Radiological Protection. Vol. 21, No. 1-3, Oxford: Pergamon, 1991.

4 Rushton V E, Horner K, Worthington H V. Aspects of panoramic radiology in general dental practice. Br Dent J 1999; 186: 342-344.

5 Faculty of General Dental Practitioners (UK). Selection criteria for dental radiography. London: Faculty of General Dental Practitioners (UK), Royal College of Surgeons of England, 1998.

6 Rushton V E, Horner K. The use of panoramic radiology in dental practice. J Dent 1996; 24: 185-201.

7 Rushton V E, Horner K, Worthington H V. Factors influencing the prescription of panoramic radiology in general dental practice. J Dent 1999; 27: 565-571.

8 Whaites E. Bitewing radiography. In: Whaites E. Essentials of dental radiography and radiology. 2 nd ed, pp 91-98. Edinburgh: Churchill Livingstone, 1996.

9 Dental Practice Board. Personal Communication. Dental Data Services, Dental Practice Board for England and Wales. 1999.

10 Cohen J. A coefficient of agreement for nominal scales. Educ Psychol Measur 1960; 20: 37-46.

11 Landis J R, Koch G G. The measurement of observer agreement for categorical data. Biometrics 1977; 33: 159-174.

12 Office for National Statistics. Adult Dental Health Survey. Oral Health in the United Kingdom 1998. London: The Stationery Office, 2000.

13 Osman F, Scully C, Dowell T B, Davies R M. Use of panoramic radiographs in general dental practice in England. Community Dent Oral Epidemiol 1986; 14: 8-9.

14 Goldman M, Pearson A H, Darzenta N. Reliability of radiographic interpretations. Oral Surg Oral Med Oral Pathol 1974; 38: 287-293.

15 Mileman P, Purdell-Lewis D, Van der Weele L. Variation in radiographic caries diagnosis and treatment decisions among university teachers. Community Dent Oral Epidemiol 1982; 10: 329-334.

16 Gelfand M, Sunderman E J, Goldman M. Reliability of radiographical interpretations. J Endod 1983; 9: 71-75.

17 Wahab M H A, Greenfield T A, Swallow J N. Interpretation of intraoral periapical radiographs. J Dent 1984; 12: 302-313.

18 Espelid I, Tveit A B, Fjelltveit A. Variation among dentists in radiographic detection of occlusal caries. Caries Res 1994; 28: 169-175.

19 Lazarchik D A, Firestone A R, Heaven T J, Fuller S J, Lussi A. Radiographic evaluation of occlusal caries: effect of training and experience. Caries Res 1995; 29: 355-358.

20 Robinson P J A. Radiology's achilles' heel: error and variation in the interpretation of the Rontgen image. Br J Radiol 1997; 70: 1085-1098.

21 White S C, Pharoah M J. Periodontal Diseases. In: White S C, Pharoah M J (Eds.). Oral Radiology: Principles and Interpretation. 4th ed, pp. 290-302. St. Louis: Mosby, 1999.

22 Stephens R G, Kogon S L, Reid J A. Prescription radiography. A new concept for radiation protection in dental practice. Can Dent Assoc J 1985; 9: 672-679.

23 Marken K E. Studies of deviations between observers in clinico-odontological recording. Publications of the Umea Research Library Series; 2: No 8. Uppsala: Almqvist \& Wiksells, 1962.

24 Koran L M. The reliability of clinical methods, data and judgements. $N$ Engl J Med 1975; 293: 642-646 and 695-701.

25 White S C, Forsythe A B, Joseph L P. Patient-selection criteria for panoramic radiography. Oral Surg Oral Med Oral Pathol 1984; 57: 681-690.

26 Kostopoulou O, Brickley M R, Shepherd J P, Newcombe R G. Perceived risk of future pathology associated with pathology-free third molars: a comparison of oral and maxillofacial surgeons and family dentists. $\mathrm{Br}$ Dent J 2000; 188: 28-31.

27 National Institute for Clinical Excellence. Technology Appraisals Guidance- No 1. Guidance on the removal of wisdom teeth. London: National Institute for Clinical Excellence, 2000.

28 Barratt A P, Waters B E, Griffiths, C J. A critical evaluation of panoramic radiography as a screening procedure in dental practice. Oral Surg Oral Med Oral Pathol 1984; 57: 673-677.

29 Osborne G E, Hemmings K W. A survey of disease changes observed on dental panoramic tomographs taken of patients attending a periodontology clinic. Br Dent J 1992; 173: 166-168.

30 Akerblom A, Rohlin M, Hasselgren G. Individualised restricted intraoral radiography versus full-mouth radiography in the detection of periradicular lesions. Swed Dent J 1986; 12: 151-159.

31 Brooks S L, Cho S Y. Validation of a specific selection criterion for dental periapical radiography. Oral Surg Oral Med Oral Pathol 1993; 75: 383-386.

32 Brooks S L. A study of selection criteria for intraoral dental radiography. Oral Surg Oral Med Oral Pathol 1986; 62: 234-239.

33 Richardson P S. Selected periapical radiology compared to panoramic screening. Primary Dent Care 1997; 4: 95-99. 